Pacific Journal of Mathematics

TRRONGLY BOONDED OPFRATOO 


\title{
STRONGLY BOUNDED OPERATORS
}

\author{
Paul W. LeWis
}

\begin{abstract}
Recently Dobrakov, Batt and Berg, and Brooks and Lewis have studied the class of strongly bounded operators on continuous function spaces in detail. In many cases, these operators coincide with the weakly compact operators and therefore form a norm-closed two-sided ideal; and it is known in general that the strongly bounded operators form a normclosed left ideal. In this note an example is presented which shows that the strongly bounded operators do not form a right ideal.
\end{abstract}

Let each of $E$ and $F$ denote a $B$-space, let $H$ denote a locally compact Hausdorff space, and let $\boldsymbol{B} \equiv C_{0}(H, E)$ be the $B$-space (under sup norm) of all continuous $E$-valued functions defined on $H$ which vanish at infinity. It is known that if an operator (=continuous linear transformation) $L$ maps $B$ into $F$ and $\Sigma=\Sigma(H)$ is the Borel $\sigma$-algebra of subsets of $H$, then there is a unique weakly regular finitely additive representing measure $m: \Sigma \rightarrow B\left(E, F^{* *}\right)$ so that $L(f)=\int f d m, f \in \boldsymbol{B}$, e.g., see Batt and Berg [1] and Brooks and Lewis [3] for further details.

The representing measure $m: \Sigma \rightarrow B\left(E, F^{* *}\right)$ is said to be strongly bounded ( $s$-bounded) provided that if $\left(A_{2}\right)$ is a disjoint sequence, then $\tilde{m}\left(A_{i}\right) \rightarrow 0$, where $\widetilde{m}$ denotes the semivariation of $m$; an operator will be called $s$-bounded if its representing measure is $s$-bounded. Equivalent formulations are given in the following lemma, which we state for reference purposes. For the details of the proof, one may consult Brooks and Lewis [3].

Lemma 1. Suppose that $m$ is a representing measure, $m \leftrightarrow L$. Then the following are equivalent:

(a) $m$ is s-bounded;

(b) $\tilde{m}\left(A_{2}\right) \rightarrow 0$ whenever $A_{i} \searrow \varnothing$;

(c) $\left\{\left|m_{z}\right|: z \in F_{1}^{*}\right\}$ is conditionally weakly compact in $\operatorname{ca}\left(\Sigma, E^{*}\right)$;

(d) $\operatorname{\Sigma m}\left(A_{i}\right) x_{i}$ converges (in $F$ ) for each disjoint sequence $\left(A_{i}\right)$ and $\left(x_{i}\right) \subset E_{1}(=$ closed unit ball of $E)$;

(e) If $\left(A_{i}\right) \subset \Sigma$ and $A_{i} \searrow \varnothing$, then there is a nested sequence $U_{n}$ of open sets so that $A_{n} \subset U_{n}$ and $L\left(f_{n}\right) \rightarrow 0$ uniformly for each sequence $\left(f_{n}\right)$ so that support $\left(f_{n}\right) \subset U_{n},\left\|f_{n}\right\| \leqq 1$.

The class of $s$-bounded operators which we denote by $S$ has been studied in [1], [2], [3], and [5], with the sharpest results being 
presented in $\S 4$ of [3]. In particular, if $E$ is reflexive, then $L \in S$ if and only if $L$ is weakly compact. Dobrakov proved in [5] that if $F=\boldsymbol{B}$, then $S$ is a norm-closed left ideal. Part (e) of Lemma 1 also provides a simple proof of this fact. However, the question of whether $S$ is a two-sided ideal is apparently open; the following example answers this question in the negative and thereby settles a problem raised in [3] and [5]. Consequently, while $S$ coincides with the weakly compact operators in many cases, in general it differs not only in terms of mapping properties but also in terms of algebraic structure.

ExAmple. For each positive integer $n$, let $E^{2 n+1}$ denote Euclidean $2 n+1$ dimensional space equipped with the $l^{1}$-norm, and let $E$ be the substitution or product space $P_{l} \infty\left(E^{2 n+1}\right)$ [4, p. 31]. Let $e_{i, j_{i}}$ be that point in $E$ with 1 in the $j_{2}$-component of the $i$ th coordinate and 0 otherwise. For $n$ a positive integer, set $A_{n}=(1 /(n+1), 1 / n)$ and partition $A_{n}$ into $2 n+1$ disjoint subintervals of equal length. Denote these sets by $a_{n, i_{n}}, 1 \leqq i_{n} \leqq 2 n+1$. Equip $\Gamma=\left\{a_{i, j_{i}}: i \geqq 1,1 \leqq j_{2} \leqq 2 i+1\right\}$ with the discrete topology, and let $H$ denote the one-point compactification of this set, with the point at infinity denoted by $a_{0,0}$. Let $\nu$ denote Lebesgue measure, where we put $\nu\left(a_{0,0}\right)=0$; and if $A \in \Sigma(H)$, then define $\lambda(A)=\Sigma \nu\left(a_{i, j}\right), a_{\imath, j} \subset A$. Notice that if $x \in E$ and we put $x(t)=x$ for each $t \in H$, then $E$ is isometrically isomorphic to a subspace of $C(H, E)$. Now define $L: C(H, E) \rightarrow E G C(H, E)$ by setting $L(f)=\int f d \lambda$; then $L$ is an operator, $L(x)=x$ for each $x \in E$, and $L$ is $s$-bounded since $\lambda$ is countably additive with finite total variation. However, $L$ is not weakly compact since $E$ is not reflexive and thus $E_{1}=L\left(C(H, E)_{1}\right)$ is not weakly compact.

If $S_{E}(\Sigma(\Gamma))$ denotes the $E$-valued simple functions and $U_{E}(\Sigma(\Gamma))$ denotes their uniform closure, then $C_{0}(\Gamma, E) \subset \overline{S_{E}(\Sigma(\Gamma))}=U_{E}(\Sigma(\Gamma))$. Therefore, to define an operator $U$ on $C_{0}(\Gamma, E)$, it suffices to define $U$ on $S_{E}(\Sigma(\Gamma))$. If $\xi_{A}$ denotes the characteristic function of $A \in \Sigma(\Gamma)$ and $x=\left(x_{\imath}, j_{i}\right) \in E$, then we define $U\left(\xi_{A} x\right)$ by the following equation:

$$
P_{\imath, j_{i}}\left(U\left(\xi_{A} x\right)\right) \begin{cases}x_{i, j_{i}} & \text { if } a_{i, j_{i}} \in A, \\ 0 & \text { otherwise },\end{cases}
$$

where $P_{i, j_{i}}$ is the projection on the $j_{2}$-component of the $i$ th coordinate. Now extend $U$ by linearity to all of $S_{E}(\Sigma(\Gamma))$; it is not difficult to see that $U$ is well-defined, linear, and $\|U\| \leqq 1$. Hence we may consider $U$ to be defined on all of $C_{0}(\Gamma, E)$.

Then if $f \in C(H, E)$, let $f_{0}(\cdot)=f(\cdot)-f\left(a_{0,0}\right) \in C_{0}(\Gamma, E)$, and define $V(f)$ to be $U\left(f_{0}\right)$. It follows that $V$ is linear and continuous. Further, if $\mu$ is the representing measure for $V$, then $L \circ \mu$ is the representing measure for $L \circ V$, and $\sum_{i=1}^{\infty} L\left[\mu\left(\left\{a_{\imath, 1_{i}}\right\}\right) e_{i, 1_{i}}\right]=\sum L\left[U\left(\xi_{\left\{a_{i}, 1_{i}\right\rangle} e_{i, 1_{i}}\right)\right]=$ 
$\sum L\left(e_{i, 1_{i}}\right)=\sum e_{i, 1_{i}}$, and this series clearly does not converge in $E$. Thus $L \circ V$ is not $s$-bounded. In fact, the representing measure for $L \circ V$ is not even countably additive. For if $\varphi \in E_{1}$ so that $P_{i, 1_{i}}(\varphi)=1$ for each $i$, then $\sum L\left[\mu\left(\left\{a_{i, 1_{i}}\right\}\right) \varphi\right]=\sum L\left(e_{i, 1_{i}}\right)$, a divergent series.

\section{REFERENCES}

1. Jurgen Batt and E. Jeffrey Berg, Linear bounded transformations on the space of continuous functions, J. Functional Analysis, 4 (1969), 215-239.

2. James K. Brooks and Paul W. Lewis, Operators on function spaces, Bull. Amer. Math. Soc., 78 (1972), 697-701.

3. L Linear operators and vector measures, Trans. Amer. Math. Soc., 192 (1974), 139-162.

4. M. M. Day, Normed Linear Spaces, Springer-Verlag, New York, 1962.

5. I. Dobrakov, On representation of linear operators on $C_{0}(T, X)$, Czech. Math. J., 21 (96) (1971), 13-30.

Received May 15, 1973.

North Texas State University 



\section{PACIFIC JOURNAL OF MATHEMATICS}

\section{EDITORS}

RICHARD ARENS (Managing Editor)

University of California

Los Angeles, California 90024

R. A. Beaumont

University of Washington

Seattle, Washington 98105
J. DugundJI

Department of Mathematics

University of Southern California

Los Angeles, California 90007

D. Gilbarg and J. Milgram

Stanford University

Stanford, California 94305

\section{ASSOCIATE EDITORS}

E. F. BECKENBACH

B. H. NeUMANN

F. WOLF

K. YosHIDA

\section{SUPPORTING INSTITUTIONS}

UNIVERSITY OF BRITISH COLUMBIA

CALIFORNIA INSTITUTE OF TECHNOLOGY

UNIVERSITY OF CALIFORNIA

MONTANA STATE UNIVERSITY

UNIVERSITY OF NEVADA

NEW MEXICO STATE UNIVERSITY

OREGON STATE UNIVERSITY

UNIVERSITY OF OREGON

OSAKA UNIVERSITY
UNIVERSITY OF SOUTHERN CALIFORNIA

STANFORD UNIVERSITY

UNIVERSITY OF TOKYO

UNIVERSITY OF UTAH

WASHINGTON STATE UNIVERSITY

UNIVERSITY OF WASHINGTON

$\stackrel{*}{*} \stackrel{*}{*} \stackrel{*}{*}$ AMERICAN MATHEMATICAL SOCIETY




\section{Pacific Journal of Mathematics}

\section{Vol. 53, No. $1 \quad$ March, 1974}

Martin Bartelt, Strongly unique best approximates to a function on a set, and a finite

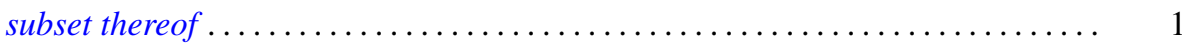

S. J. Bernau, Theorems of Korovkin type for $L_{p}$-spaces $\ldots \ldots \ldots \ldots \ldots \ldots \ldots \ldots \ldots$

S. J. Bernau and Howard E. Lacey, The range of a contractive projection on an

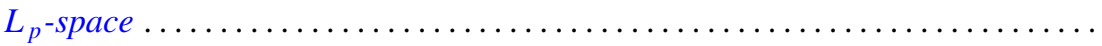

Marilyn Breen, Decomposition theorems for 3-convex subsets of the plane ......... Ronald Elroy Bruck, Jr., A common fixed point theorem for a commuting family of

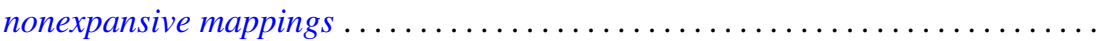

Aiden A. Bruen and J. C. Fisher, Blocking sets and complete $k$-arcs . . . . . . . 73

R. Creighton Buck, Approximation properties of vector valued functions . ......... 85

Mary Rodriguez Embry and Marvin Rosenblum, Spectra, tensor products, and

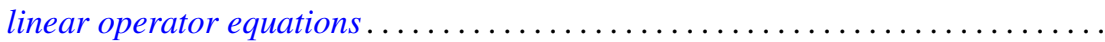

Edward William Formanek, Maximal quotient rings of group rings . . . . . . . . . 109

Barry J. Gardner, Some aspects of T-nilpotence . . . . . . . . . . . . . . . 117

Juan A. Gatica and William A. Kirk, A fixed point theorem for $k$-set-contractions

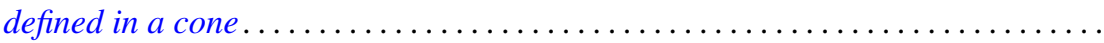

Kenneth R. Goodearl, Localization and splitting in hereditary noetherian prime

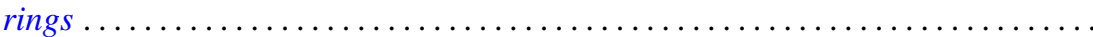

James Victor Herod, Generators for evolution systems with quasi continuous

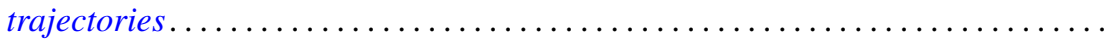

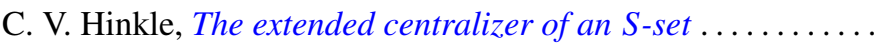

I. Martin (Irving) Isaacs, Lifting Brauer characters of p-solvable groups . . .

Bruce R. Johnson, Generalized Lerch zeta function ...........

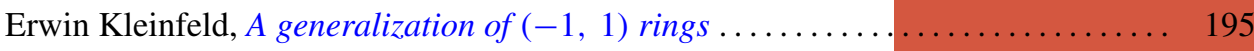

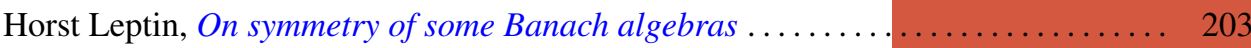

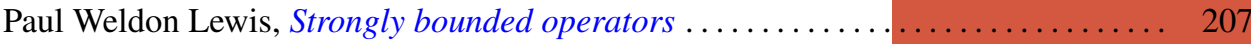

Arthur Larry Lieberman, Spectral distribution of the sum of self-adjoint

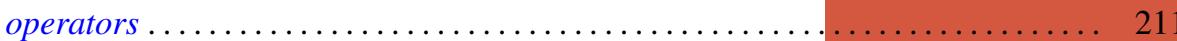

I. J. Maddox and Michael A. L. Willey, Continuous operators on paranormed spaces and matrix transformations

James Dolan Reid, On rings on groups ........................... 229

Richard Miles Schori and James Edward West, Hyperspaces of graphs are Hilbert cubes.

William H. Specht, A factorization theorem for p-constrained groups ...

Robert L Thele, Iterative techniques for approximation of fixed points of certain nonlinear mappings in Banach spaces ...............

Tim Eden Traynor, An elementary proof of the lifting theorem

Charles Irvin Vinsonhaler and William Jennings Wickless, Completely decomposable groups which admit only nilpotent multiplications .

Raymond O’Neil Wells, Jr, Comparison of de Rham and Dolbeault cohomology for

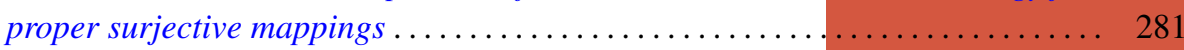

David Lee Wright, The non-minimality of induced central representations . . . . . 301 